\title{
ANALISIS PENGARUH TAHUN PERAKITAN TERHADAP EMISI GAS BUANG KENDARAAN BERMOTOR
}

\author{
Syahril Machmud ${ }^{1)}$, Untoro Budi Surono ${ }^{2)}$, Toyib Hasanudin ${ }^{3)}$. \\ 1), 2) Teknik Mesin Universitas Janabadra, Yogyakarta \\ 3). Alumni Teknik Mesin Universitas Janabadra, Yogyakarta \\ *E-mail : syahril@ Janabadra.ac.id.
}

\begin{abstract}
Abstrak
Seiring dengan peningkatan kebutuhan masyarakat, maka aktifitas transportasi pun juga meningkat. Transportasi merupakan salah satu kegiatan yang berkontribusi besar sebagai penghasil emisi gas buang kendaraan bermotor khususnya yang berbahan bakar bensin. Mengakibatkan tingginya kadar polusi udara akibat emisi gas buang dari kendaraan bermotor. Polusi utama yang dihasilkan dari emisi gas buang kendaraan bermotor adalah Karbon monoksida (CO), Hidrokarbon (HC), Karbon dioksida (CO2), Oksigen (O2) dan Nitrogen oksida (NOx). Gas buang yang dikeluarkan kendaraan bermotor sangat berbahaya bagi kesehatan manusia. Penelitian ini dilakukan untuk mengetahui pengaruh tahun perakitan terhadap emisi gas buang kendaraan bermotor. Peralatan yang digunakan dalam penelitian ini adalah Alat uji emisi kendaraan bensin ( Emisi Gas Analyzer) merek SPTC. Metode yang digunakan dalam penelitian ini adalah metode deskriptif dan analisis. Hasil penelitian menunjukkan Secara keseluruhan dengan menggunakan ketentuan ambang batas bagi mobil lama $(<2007)$, yakni CO 4,5 \% dan HC 1200 ppm, maka hanya 29,05 \% dari seluruh kendaraan bermotor yang dikaji mengalami tidak lulus uji emisi, akan tetapi jika menggunakan ketentuan ambang batas bagi mobil baru ( $\geq 2007)$, yakni CO 1,5\% dan HC 200 ppm, maka 63,2 \% dari seluruh kendaraan bermotor yang dikaji mengalami lulus uji emisi atau 36,8 \% kendaraan memiliki emisi gas buang yang melebihi ambang batas yang ditetapkan.
\end{abstract}

Kata Kunci: Emisi Gas Buang, Tahun Perakitan, Motor Bakar Bensin.

\section{Abstract}

As society's needs increase, so does transportation activity. Transportation is one of the major contributors that produce gas emissions from motor vehicles, especially the ones that burn using gasoline. It results in a high level of air pollution caused by gas emissions discharge from motor vehicles. The main pollutants produced by gas emissions discharge from motor vehicles are carbon monoxide $(\mathrm{CO})$, hydrogen carbon (HC), carbon dioxide (CO2), oxygen (O2), and nitrogen oxide (NOx). The gas that is thrown out of motor vehicles is extremely dangerous to human health. The purpose of this research is to determine the impact of the years of assembly on gas emissions produced from motor vehicles. The equipment used in this research is an Emission Gas Analyzer SPTC brand. The method used in this research is descriptive and analytical. Research results show that overall using the limit values for old cars (< 2007), only $29.05 \%$ of all tested motor vehicles have failed emission tests, but using the limit values for new vehicles $(\geq 2007)$, (CO 1.5\% and HC 200 ppm), resulting in $63.2 \%$ of all motor vehicles tested pass emissions tests or $36.8 \%$ of the sample of emissions test exhaust exceeding the prescribed limits.

Keywords: Gas emision. Year of asemby, gasoline combustion. 


\section{PENDAHULUAN}

Sejalan dengan pesatnya pembangunan dan jumlah penduduk yang tinggal di Kabupaten Temanggung, maka jumlah kendaraan bermotor juga mengalami peningkatan. Dengan semakin meningkatnya kendaraan bermotor yang beroperasi di jalan, maka akan menyebabkan peningkatan pada konsentrasi pencemarnya sehingga dikhawatirkan membahayakan kesehatan manusia dan mempengaruhi kualitas udara apabila melebihi ambang batas yang ditentukan. Untuk itu perlu diselenggarakan pengujian terhadap kendaraan yang beroperasi di Kabupaten Temanggung melalui Pengujian Kendaraan bermotor untuk mengetahui kendaraan tersebut memenuhi Persyaratan Teknis dan Laik Jalan .

Saat ini emisi gas buang hasil pembakaran mesin kendaraan bermotor merupakan faktor penyebab polusi yang paling dominan. Hasil penelitian menunjukan bahwa kontribusi pencemaran udara yang berasal dari sektor transportasi berkontribusi sebanyak 60-70\%. Sedangkan kontribusi gas buang dari cerobong asap industri hanya berkisar $10-15 \%$, sisanya berasal dari sumber pembakaran lain, misalnya dari rumah tangga pembakaran sampah, dan kebakaran hutan. Sebenarnya banyak polutan udara yang perlu diwaspadai, tetapi organisasi kesehatan dunia word health organization (WHO) menetapkan beberapa jenis polutan yang dianggap serius.

Sumber emisi gas buang dari proses pembakaran bahan bakar motor menghasilkan gas buang yang secara teoritis mengandung unsur air (H2O), hidrokarbon (HC), karbon monoksida (CO), karbon dioksida (CO2), dan senyawa nitrogen oksida (NOx), nitrogen dioksida (NO2) dan sulfur dioksida (SO2) [1]. Karbon monoksida (CO) dan hidrokarbon (HC) merupakan polutan utama yang keluar dari gas buang kendaraan bermotor yang sangat berbahaya. Karbon monoksida (CO) yang keluar dari knalpot akan berada di udara ambien, jika terhirup oleh manusia maka molekul tersebut akan masuk kedalam saluran pernapasan lalu masuk ke dalam paru-paru dan kemudian akan menempel pada haemoglobin darah membentuk Carboxy Haemoglobin ( $\mathrm{COHb}$ ). Semakin tinggi konsentrasi karbon monoksida (CO) yang terhirup oleh manusia maka semakin fatal resiko yang diterima oleh manusia tersebut, bahkan dapat menyebabkan kematian. Sementara hidrokarbon (HC) merupakan pencemar utama yang berasal dari kendaraan bermotor lalu lintas di dalam perkotaan. Di beberapa kota besar, sebagai pencemar primer dan yang memberikan kontribusi terbesar dalam pencemaran oksidan fotokimia. Hidrokarbon (HC) yang ada pada gas buang adalah dari senyawa bahan bakar yang tidak terbakar habis dalam proses pembakaran pada kendaraan. Hidrokarbon (HC) Efeknya dapat menyebabkan 
gangguan pada kesehatan terutama pada selaput lendir, mata, hidung dan tenggorokan dan jika terakumulasi dalam waktu yang agak lama Hidro karbon juga berpotensial menyebabkan penyakit kanker [2].

Pencemaran udara dari sumber emisi gas buang semakin meningkat setiap tahunnya. Emisi gas buang seperti karbon monoksida (CO), hidrokarbon (HC), dan nitrogen dioksida (NO2) dapat menyebabkan terjadinya peningkatan suhu rata-rata permukaan bumi yang dikenal juga dengan pemanasan global. Kadar emisi gas karbon monoksida (CO) berkisar 185 juta ton, hidrokarbon (HC) berkisar 2,5 juta ton, nitrogen dioksida (NO2) berkisar 1,2 juta ton per tahunnya [3].

Pada dasarnya jenis bahan pencemar yang dikeluarkan semua jenis kendaraan adalah sama hanya komposisinya saja yang berbeda karena adanya perbedaan kondisi dan sistem operasi mesin kendaraan yang satu dengan yang lainnya. Kendaraan yang perakitan terbaru umumnya memiliki kadar emisi gas buang yang lebih rendah dibandingkan dengan kendaraan yang lebih tua umurnya apabila tidak melakukan perawatan dengan tepat dan rutin.

Pemerintah telah menerapkan berbagai kebijakan untuk mengendalikan tingkat pencemaran udara di perkotaan akibat kendaraan bermotor melalui tentang Ambang Batas Emisi Gas Buang Kendaraan bermotor tipe lama[4].

\section{METODE PENELITIAN}

Metode yang digunakan dalam penelitian ini adalah metode deskriptif dan analisis. Kendaraan bermotor yang digunakan sebagai obyek penelitian adalah kendaraan bermotor bermesin bensin jenis roda empat (mobil) merek Suzuki, Mitsubishi dan Daihatsu. Kadar emisi gas buang yang dikaji meliputi karbon monoksida (CO), hidrokarbon (HC), dimana pengukurannya dilakukan dengan menggunakan analyzer digital merek SPTC.

Dalam penelitian ini, langkah penelitian yang dilakukan dapat digambarkan seperti bagan alir dibawah ini : 


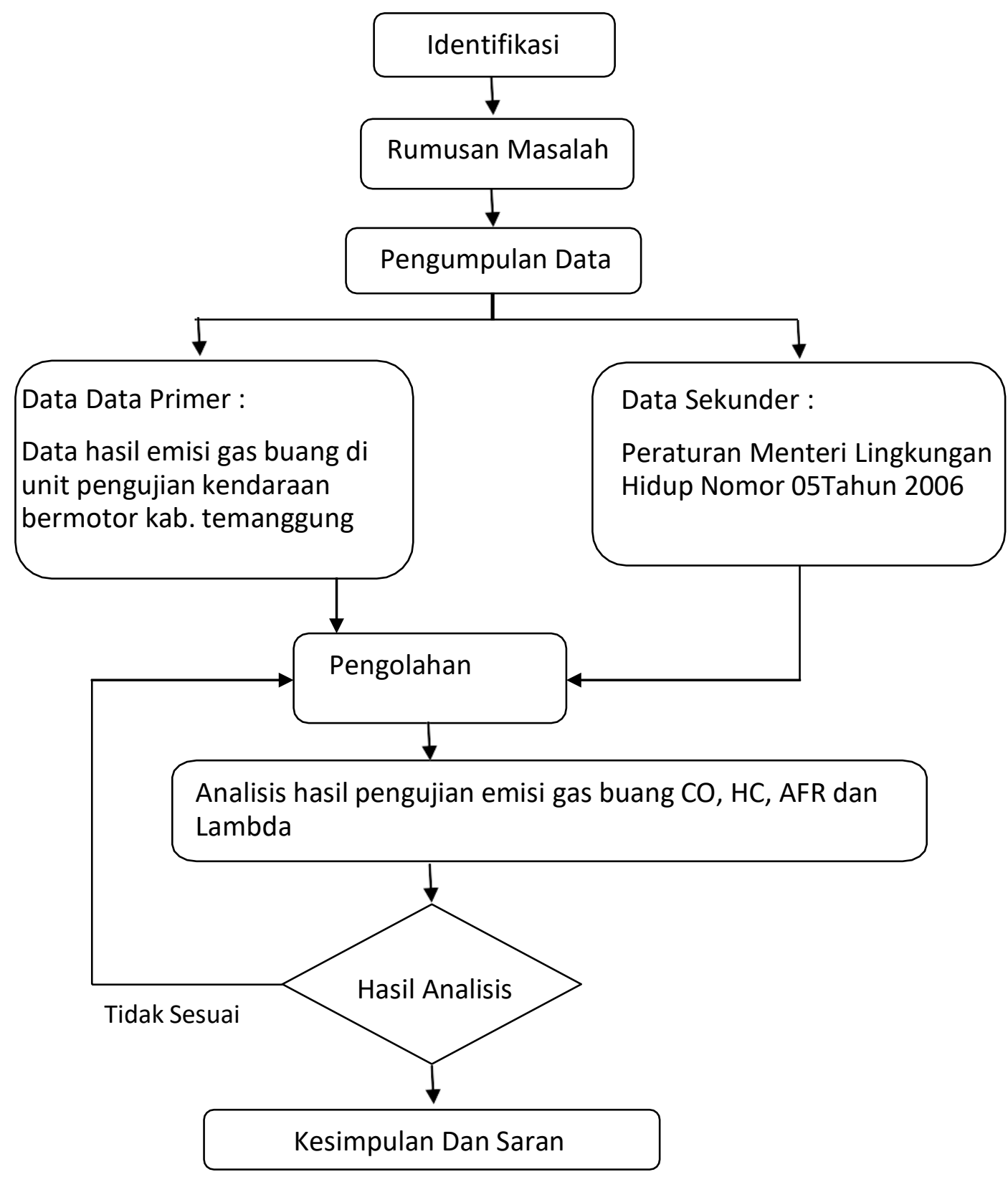

Gambar 1. Diagram alir proses penelitian

\section{HASIL DAN PEMBAHASAN}

\section{a. Hasil Pengujian Emisi Gas Buang Karbon Monoksida (CO)}

Dari hasil uji emisi gas buang, data-data yang diperoleh dianalisis untuk memperoleh kesimpulan pengaruh tahun perakitan kendaraan dari berbagai merek, berpengaruh terhadap kadar emisi gas buang karbon monoksida $(\mathrm{CO})$. Hasil rata-rata dapat dibaca pada Tabel 1 :

Tabel 1. Hasil pengujian emisi gas buang CO (\%)

\begin{tabular}{|c|c|c|c|c|c|}
\hline \multirow{2}{*}{ NO } & TAHUN & JUMLAH & \multicolumn{3}{|c|}{ MEREK } \\
\cline { 4 - 6 } & PERAKITAN & SAMPEL & MITSUBISHI & SUZUKI & DAIHATSU \\
\hline 1 & 1990 & 14 & 4,90 & 5,17 & 6,17 \\
\hline 2 & 1991 & 3 & 4,96 & 3,33 & 6,3 \\
\hline
\end{tabular}

Analisis Pengaruh Tahun Perakitan Terhadap Emisi Gas Buang Kendaraan Bermotor (Syahril Machmud, Untoro Budi Surono, Toyib Hasanudin) 


\begin{tabular}{|c|c|c|c|c|c|}
\hline 3 & 1992 & 5 & 4,67 & 4,12 & 3,55 \\
\hline 4 & 1993 & 6 & 5,75 & 3,42 & 3,11 \\
\hline 5 & 1994 & 8 & 5,26 & 4,53 & 3,9 \\
\hline 6 & 1995 & 14 & 3,24 & 5,53 & 3,55 \\
\hline 7 & 1996 & 8 & 3,86 & 3,22 & 3,88 \\
\hline 8 & 1997 & 15 & 3,31 & 2,16 & 3,69 \\
\hline 9 & 1998 & 8 & 2,58 & 4,49 & 3,10 \\
\hline 10 & 1999 & 9 & 2,22 & 4,39 & 2,16 \\
\hline 11 & 2000 & 9 & 1,87 & 1,96 & 2,55 \\
\hline 12 & 2001 & 11 & 3,70 & 1,97 & 1,41 \\
\hline 13 & 2002 & 15 & 3,50 & 4,00 & 2,60 \\
\hline 14 & 2003 & 26 & 2,99 & 3,58 & 2,19 \\
\hline 15 & 2004 & 26 & 3,56 & 1,93 & 1,94 \\
\hline 16 & 2005 & 27 & 2,76 & 2,93 & 1,99 \\
\hline 17 & 2006 & 31 & 0,97 & 0,82 & 1,07 \\
\hline 18 & 2007 & 29 & 0,43 & 0,46 & 0,32 \\
\hline 19 & 2008 & 28 & 0,70 & 0,46 & 0,91 \\
\hline 20 & 2009 & 30 & 0,50 & 0,53 & 0,64 \\
\hline 21 & 2010 & 29 & 0,51 & 0,46 & 0,61 \\
\hline 22 & 2011 & 30 & 0,56 & 0,65 & 0,44 \\
\hline 23 & 2012 & 30 & 0,22 & 0,31 & 0,34 \\
\hline 24 & 2013 & 31 & 0,37 & 0,49 & 0,41 \\
\hline 25 & 2014 & 30 & 0,31 & 0,40 & 0,56 \\
\hline 26 & 2015 & 30 & 0,32 & 0,15 & 0,18 \\
\hline 27 & 2016 & 30 & 0,13 & 0,11 & 0,19 \\
\hline 28 & 2017 & 30 & 0,13 & 0,26 & 0,17 \\
\hline 5476 & 0 & & 30 & & \\
\hline
\end{tabular}

Sumber : Data unit pengujian kendaraan bermotor kabupaten temanggung

Pembahasan untuk hasil pengujian emisi gas buang CO (\%) dari pengaruh tahun perakitan terhadap emisi gas buang $\mathrm{CO}(\%)$ berbagai merek, ditampilkan grafik sebagai berikut :

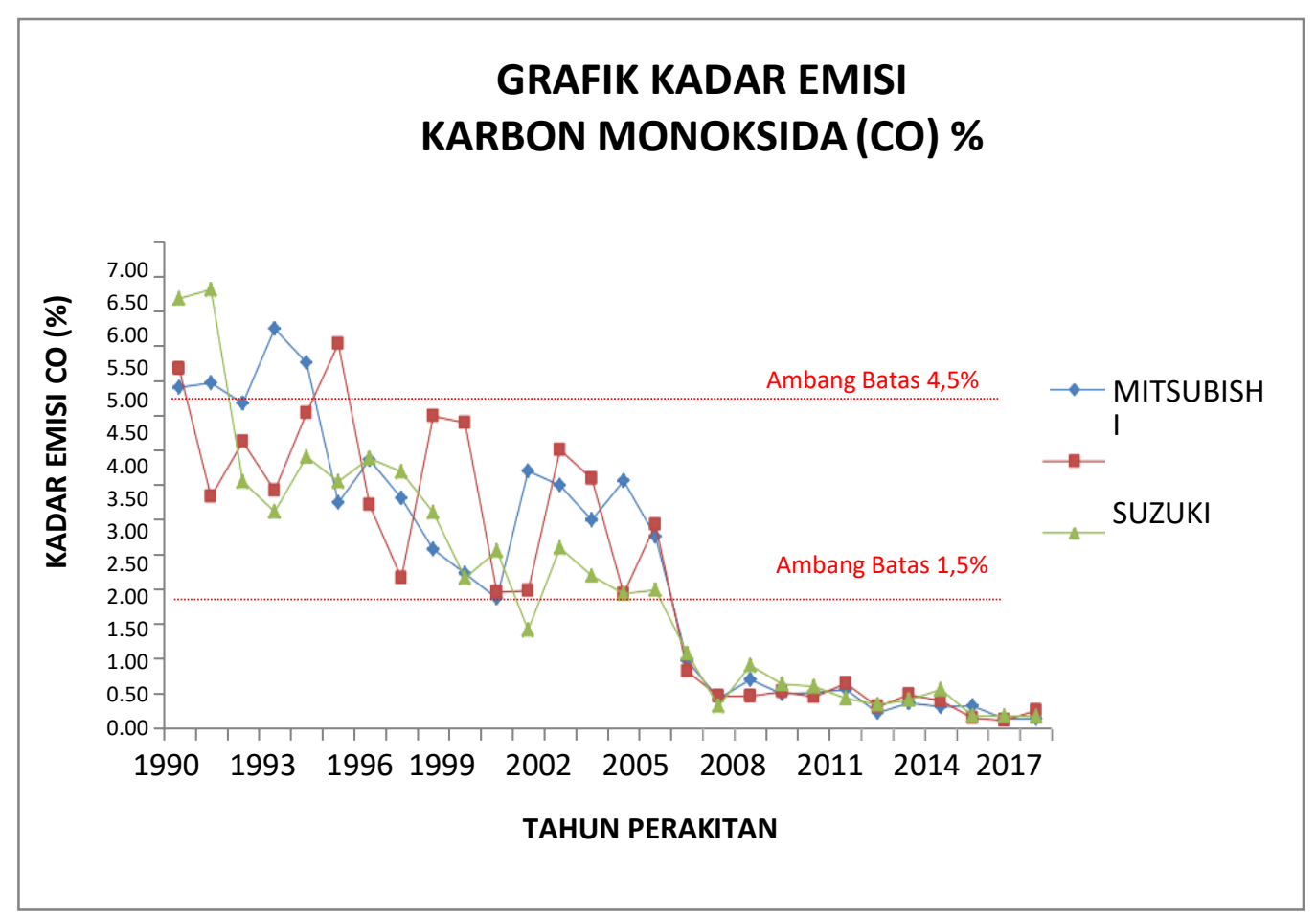

Gambar 2. Grafik emisi gas buang CO (\%) 
Dari hasil analisis emisi gas CO seperti yang ditunjukkan oleh gambar 2, sesuai dengan Peraturan Menteri Negara Lingkungan Hidup No. 5 Tahun 2006 Tentang Ambang Batas Emisi Gas Buang Kendaraan Lama dimana kendaraan bermotor yang perakitan diatas atau sama dengan tahun 2007 adalah 1,5\% sedangkan untuk kendaraan bermotor yang perakitan dibawah tahun 2007 adalah 4,5\%. Emisi gas CO yang dihasilkan kendaraan yang perakitan diatas atau sama dengan tahun 2007 dengan sample sebanyak 327 kendaraan dari berbagai merek sebagian besar telah memenuhi ambang batas 1,5\%, sedangkan emisi gas $\mathrm{CO}$ kendaraan yang perakitan kurang dari tahun 2007 dengan sample sebanyak 235 kendaraan dari berbagai merek menunjukkan hampir tidak ada kendaraan yang memenuhi ambang batas $1,5 \%$, tetapi sebagian besar kendaraan ini masih memenuhi ambang batas 4,5\%. Sedangkan untuk kendaraan yang perakitan pada kurang dari atau samadengan tahun 1996 cenderung tidak memenuhi ambang batas yang ditentukan untuk kendaraan lama, yakni 4,5\%. Maka dapat diketahui bahwa kadar emisi gas CO dari berbagai merek kendaraan yang dikaji cenderung mengalami penurunan seiring dengan semakin muda usia kendaraan. Secara umum CO menunjukkan angka efisiensi dari pembakaran di ruang bakar. Tingginya emisi CO disebabkan karena kurangnya oksigen untuk menghasilkan pembakaran yang tuntas dan sempurna.

\section{b. Hasil Pengujian Emisi Gas Buang Hidrokarbon (HC)}

Dari hasil uji emisi gas buang, data-data yang diperoleh dianalisis untuk memperoleh kesimpulan pengaruh tahun perakitan kendaraan bermotor dari berbagai merek, berpengaruh terhadap kadaremisi gas buang hidrokarbon (HC). Hasil rata-rata dapat dibaca pada Tabel 2:

Tabel 2. Hasil pengujian emisi gas buang HC, ppm

\begin{tabular}{|c|c|c|c|c|c|}
\hline \multirow{2}{*}{ NO } & TAHUN & \multirow{2}{*}{ JUMLAH } & \multicolumn{3}{|c|}{ MEREK } \\
\cline { 4 - 6 } & PERAKITAN & SAMPEL & MITSUBISHI & SUZUKI & DAIHATSU \\
\hline 1 & 1990 & 14 & 1121 & 1027 & 1200 \\
\hline 2 & 1991 & 3 & 950 & 920 & 1250 \\
\hline 3 & 1992 & 5 & 846 & 845 & 842 \\
\hline 4 & 1993 & 6 & 893 & 940 & 880 \\
\hline 5 & 1994 & 8 & 954 & 878 & 1100 \\
\hline 6 & 1995 & 14 & 1143 & 1198 & 663 \\
\hline 7 & 1996 & 8 & 400 & 962 & 615 \\
\hline 8 & 1997 & 15 & 575 & 492 & 533 \\
\hline 9 & 1998 & 8 & 713 & 854 & 655 \\
\hline
\end{tabular}

Analisis Pengaruh Tahun Perakitan Terhadap Emisi Gas Buang Kendaraan Bermotor (Syahril Machmud, Untoro Budi Surono, Toyib Hasanudin) 


\begin{tabular}{|c|c|c|c|c|c|}
\hline 10 & 1999 & 9 & 530 & 538 & 677 \\
\hline 11 & 2000 & 9 & 632 & 567 & 677 \\
\hline 12 & 2001 & 11 & 733 & 453 & 533 \\
\hline 13 & 2002 & 15 & 506 & 916 & 701 \\
\hline 14 & 2003 & 26 & 436 & 493 & 451 \\
\hline 15 & 2004 & 26 & 518 & 497 & 466 \\
\hline 16 & 2005 & 27 & 491 & 635 & 726 \\
\hline 17 & 2006 & 31 & 146 & 195 & 247 \\
\hline 18 & 2007 & 29 & 147 & 120 & 95 \\
\hline 19 & 2008 & 28 & 110 & 103 & 116 \\
\hline 20 & 2009 & 30 & 104 & 89 & 111 \\
\hline 21 & 2010 & 29 & 108 & 104 & 104 \\
\hline 22 & 2011 & 30 & 124 & 112 & 106 \\
\hline 23 & 2012 & 30 & 88 & 100 & 87 \\
\hline 24 & 2013 & 31 & 92 & 100 & 92 \\
\hline 25 & 2014 & 30 & 96 & 103 & 103 \\
\hline 26 & 2015 & 30 & 92 & 82 & 82 \\
\hline 27 & 2016 & 30 & 86 & 80 & 84 \\
\hline 28 & 2017 & 30 & 61 & 61 & 67 \\
\hline
\end{tabular}

Sumber : Data unit pengujian kendaraan bermotor kabupaten temanggung

Pembahasan untuk hasil pengujian emisi gas buang HC, ppm dari pengaruh tahun perakitan terhadap emisi gas buang HC, ppm (Part Per Million) berbagai merek, ditampilkan grafik sebagai berikut:

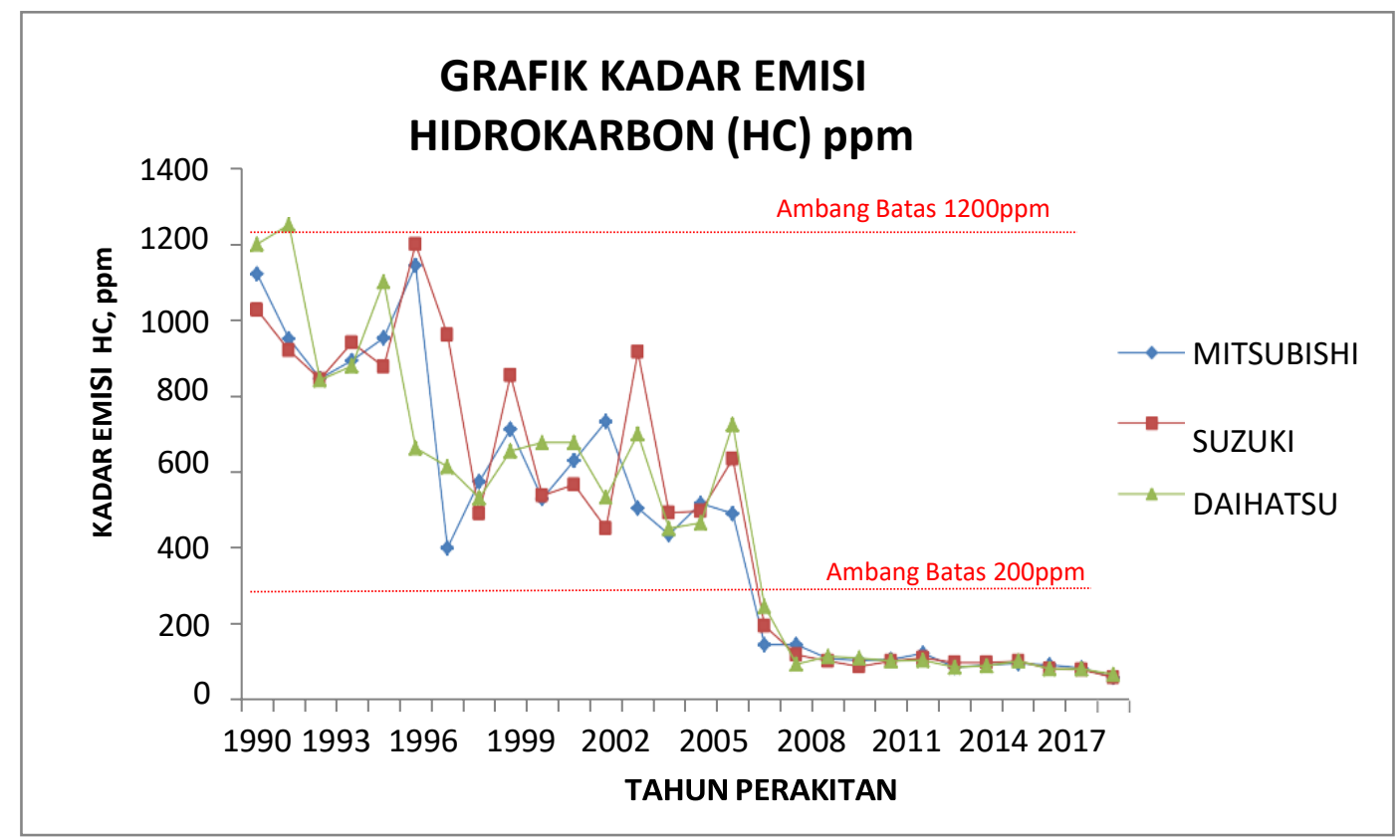

Gambar 3. Grafik emisi gas buang HC, ppm kendaraan bermotor

Dari hasil analisis emisi gas HC seperti yang ditunjukkan oleh gambar 3, sesuai dengan Peraturan Menteri Negara Lingkungan Hidup No. 5 Tahun 2006 Tentang Ambang Batas Emisi Gas Buang Kendaraan Lama dimana kendaraan bermotor yang perakitan diatas atau sama dengan tahun 2007 adalah 200ppm sedangkan untuk kendaraan bermotor yang perakitan dibawah tahun 2007 adalah 1200 ppm. Emisi gas HC kendaraan yang perakitan diatas atau sama dengan tahun 2007 dengan 
sample sebanyak 327 kendaraan dari berbagai merek sebagian besar telah memenuhi ambang batas 200 ppm, sedangkan emisi gas HC kendaraan yang perakitan kurang dari tahun 2007 dengan sample sebanyak 235 kendaraan dari berbagai merek sebagian besar tidak memenuhi ambang batas 200 ppm. Walaupun, sebagian besar kendaraan yang perakitan kurang dari tahun 2007 masih memenuhi ambang batas kendaraan lama yaitu 1200 ppm. Maka dapat diketahui bahwa kadar emisi gas HC dari berbagai merek kendaraan yang dikaji cenderung mengalami penurunan seiring dengan semakin muda usia kendaraan. Kadar HC tinggi pada umumnya kondisi ini menunjukkan adanya kelebihan bensin yang tidak terbakar yang disebabkan karena kegagalan sistem pengapian atau pembakaran yang tidak sempurna.

\section{KESIMPULAN}

Dari hasil penelitian tentang analisis pengaruh tahun perakitan terhadap emisi gas buang kendaraan bermotor, dapat disimpulkan :

a. Hasil analisis menunjukkan emisi gas buang kendaraan sangat dipengaruhi oleh umur kendaraan.

b. Emisi gas CO yang dihasilkan oleh berbagai kendaraan bermotor yang diteliti cenderung mengalami penurunan seiring dengan semakin muda usia kendaraan dan Emisi gas CO yang dihasilkan kendaraan yang perakitan tahun diatas atau sama dengan 2007 sebagian besar telah memenuhi ambang batas CO 1,5\%.

c. Emisi gas $\mathrm{HC}$ yang dihasilkan oleh berbagai kendaraan bermotor yang dikaji cenderung mengalami penurunan seiring dengan semakin muda usia kendaraan dan Emisi gas HC yang dihasilkan kendaraan yang perakitan tahun diatas atau sama dengan 2007 sebagian besar telah memenuhi ambang batas HC 200 ppm.

d. Dari hasil kajian secara keseluruhan diketahui bahwa umur ideal kendaraan, terutama kendaraan umum, adalah berkisar di atas atau sama dengan tahun 2007 karena umur kendaraan dengan umur tersebut mampu memenuhi ambang batas yang ditentukan untuk mobil baru, yakni $\mathrm{CO}$ $1,5 \%$ dan HC 200 ppm. 


\section{DAFTAR PUSTAKA}

[1] D. Setyawan, "Analisa Sistem Pengapian Pada Sepeda Motor Terhada Performa dan Emisi Gas Buang yang Memakai Bahan Bakar Premium, Pertalite, dan Pertamak," Universitas Muhammadiyah pontianak, Pontianak, Kalimantan Timus, 2020.

[2] N. E. Jayanti, M. Hakam dan I. Santiasih, "EMISI GAS CARBON MONOOKSIDA (CO) DAN HIDROCARBON (HC) PADA REKAYASA JUMLAH BLADE TURBO VENTILATOR SEPEDA MOTOR SUPRA X 125 TAHUN 2006," Jurnal Teknik Mesin Rotasi, vol. 16, no. 2, pp. 1-6, 2014.

[3] Badan Lingkungan Hidup (BLH), "Proyeksi Bahan Pencemaran Udara Menurut Sumber di Jawa Tengah,” Badan Lingkungan Hidup (BLH) Provinsi Jawa Tengah, Semarang, 2013.

[4] KLH, "PERATURAN MENTERI NEGARA LINGKUNGAN HIDUP NOMOR 05 TAHUN 2006 TENTANG AMBANG BATAS EMISI GAS BUANG KENDARAAN BERMOTOR LAMA MENTERI NEGARA LINGKUNGAN HIDUP," 2006. [Online]. Available:

http://pbde.bppi.kemenperin.go.id/files/hukum/3\%20Permen\%20LH\%20th\%2020 06\%20No.\%2005\%20Ambang\%20Batas\%20Emisi\%20Gas\%20Buang\%20Kenda raan\%20Bermotor\%20Lama.pdf. 